\title{
Patients' perspective of pathology specimens. A prospective study
}

\author{
Y L Hock, C Balachandar, S Dicken, C Bayley, S Ramaiah
}

J Clin Pathol 2005;58:891-893. doi: 10.1136/icp.2004.023812

\begin{abstract}
Aim: To determine the degree of patients' interest in surgical pathology specimens. To assess the impact of patients' involvement in surgical pathology on their understanding of (and confidence in) the storage and use of pathology specimens.

Methods: Forty seven patients were invited to visit the pathology department and view their specimens postoperatively. Those who visited were asked to complete a questionnaire to assess the effect of the visit.

Results: Thirty three of the 47 patients wished to view their specimens, but only 14 actually made the visit. All those who visited indicated that it made them better able to understand the reason for surgery and tissue retention issues, and more likely to consent to the use of excess tissue for research.

Conclusion: In general, patients are keen to know what happens to and what is wrong with the organs removed at surgery, and their involvement in surgical pathology can have positive and beneficial effects both for themselves and the profession.
\end{abstract}

$\mathrm{R}$ ecent concerns about the circumstances in which some human organs and tissue have been removed, especially after death, have tended to overshadow the potential beneficial uses of such tissues. ${ }^{1}$ These resulted in the government introducing new legislation in the 2003 to 2004 parliamentary session to cover all aspects of tissue retention from both necropsy and surgery. ${ }^{2}$ Major concerns have been expressed that this may result in a large decrease in available tissue and organs, both for transplantation and research. ${ }^{3}$ Pathologists have a reputation of being remote from patients, ${ }^{4}$ and the public has little knowledge about pathology departments. At the same time, the necessity of some hysterectomies is now being questioned. ${ }^{5}$ With these facts in mind, we assessed patients' interest in surgical pathology specimens (uteri), and whether the involvement of patients improved their understanding of the reason for surgery and organ/tissue retention issues, and might increase the likelihood of consenting to the use of excess tissue for research.

\footnotetext{
"Pathologists have a reputation of being remote from patients, and the public has little knowledge about pathology departments"
}

\section{MATERIAL AND METHODS}

The study population comprised 52 women undergoing hysterectomy for clinically benign conditions, counselled by one of the authors ( $\mathrm{C}$ Bayley) preoperatively. The nature of the study was explained to the patients and written consent was obtained. After surgery, they contacted the histopathology department and arranged a visit. At the visit, each patient was shown the hysterectomy specimen and its macroscopic pathology, and it was explained how it had been dealt with to reach the diagnosis. The resultant paraffin wax embedded blocks and glass slides were also shown, but the microscopic findings were not demonstrated or discussed in detail. The patient then completed a questionnaire (fig 1).

\section{RESULTS}

Of the 52 women asked to participate, five cancelled their operations, making a cohort of 47 . Thirty three indicated that they wanted to view their uteri removed at surgery. However, only 14 patients visited the laboratory. Although they initially showed sufficient interest, the remaining 19 showed little enthusiasm to visit the laboratory. All 14 who viewed their specimens indicated that this made them better able to understand the reason for surgery, the role of histopathology in patients' management, and organ retention and disposal issues, and they also thought that they were now more likely to give consent for the use of tissue for research. Eleven of the 14 patients wanted digital photographs of the specimens.

\section{DISCUSSION}

Our study showed that most patients (33 of 47) were interested in seeing the pathological features of their organs removed at surgery, and 14 showed sufficiently strong interest to visit the laboratory. This finding is interesting because it is a common anecdotal conception/misconception (without supporting scientific evidence) among the medical profession that only a small number of patients are interested in what happens to their surgically removed organs. Without exception, patients who visited the department found it valuable, and that it helped to alleviate their anxieties. The following were some of the comments: "Very interesting, this should be available to everyone"; "A very useful visit, most informative". We even received "thank you" notes from some (fig 2). This suggests that the involvement of patients in histopathology could rebuild public confidence in the issues of storage and use of organ/tissue by helping to achieve a much more open relationship between patients and histopathologists.

The drawbacks of our study are the small number of patients studied and the sex and operation selection. Our cohort comprised approximately $22.5 \%$ of the clinically benign hysterectomies received in our laboratory. We intended to run the study for longer, but the Human Tissue Bill received royal assent on 15 November 2004, becoming the Human Tissue Act 2004. Although the substantive provisions of the act will only come into force on days appointed by the Secretary of State by order (to allow the Human Tissue Authority to be set up, and codes of practice to be prepared), we feel that disseminating these findings now may help in the process. Sex selection resulted from a few specific requests received before the study from women to view their 


\section{PATIENT INVOLVEMENT IN SURGICAL PATHOLOGY} Walsall Hospitals NHS Trust

Part A

Do you want to view your womb removed at surgery?

Yes/No

Part B

To be filled in after viewing the specimen.

1. Do you think viewing your womb removed at surgery made you understand the reason for surgery?

$\begin{array}{llll}\text { A) Better } & \text { B) Same C) Less }\end{array}$

2. Do you understand the role of Pathologists and the Pathology Department in patients management?

$\begin{array}{llll}\text { A) Better } & \text { B) Same C) Less }\end{array}$

3. Do you understand the role of Pathologists and the Pathology Department in the surgical organ retention and respectful disposal?
A) Better
B) Same C) Less

4. Some medical research requires excess surgical tissue (which may be from the block already taken and archived). After viewing your womb, if requested, would you be:

A) More likely to give consent for the use of tissue for research

B) No change

C) Less likely to give consent for the use of tissue for research

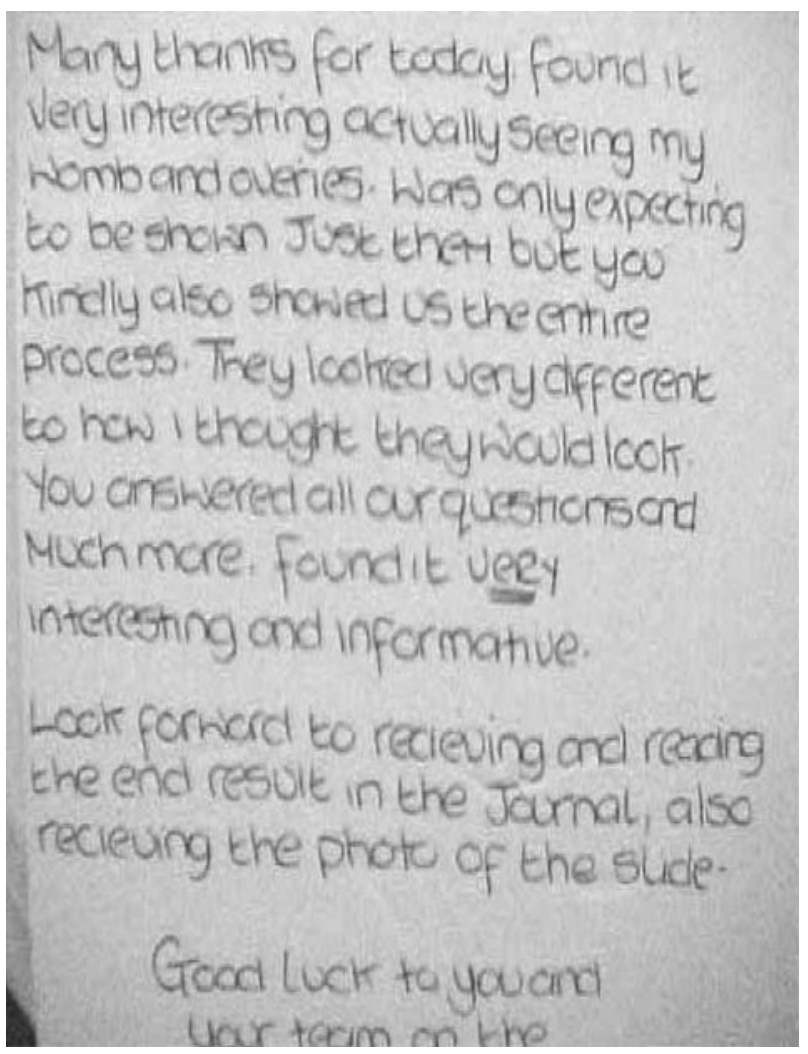

Figure 2 A "thank you" note from one of the patients who visited the laboratory. hysterectomy specimens, and from the fact that the necessity of some hysterectomies is now being questioned. Patients with suspected malignancy were excluded on ethical grounds.

"The involvement of patients in histopathology could rebuild public confidence in the issues of storage and use of organ/tissue by helping to achieve a much more open relationship between patients and histopathologists"

Despite the shortfalls, there is nothing in our opinion to indicate that this small cohort of women has significantly variant views on their surgically removed tissue/organs from the rest of the population. Because these patients were undergoing "routine" surgery, it can be argued that their views may not reflect the public view of similar issues in the emotionally charged areas of tissue/organ retention from children. Nevertheless, it is likely that any interest shown by our cohort would only be greater in these sensitive and emotional circumstances.

Currently, there is a barrier of misunderstanding between the medical profession and the public, and the involvement of patients in surgical pathology could provide one means of removing this. The pathology department is one of the few hospital departments that patients and the public have little access to, and this deepens public suspicion and misconception of pathologists. Opening up pathology departments to the public and patients may be the way forward to resolve this. Obviously, this will have major workload and financial implications. Nevertheless, we feel that the longterm gain of such a process will clearly offset any short term financial consequences. 


\section{ACKNOWLEDGEMENTS}

We thank all consultant gynaecologists who agreed for their patients to participate in this study and the 14 patients who took the time and effort to visit the laboratory. We thank Mrs S Bailey for secretarial assistance.

\section{Authors' affiliations}

Y L Hock, S Dicken, Department of Histopathology, Walsall Hospitals NHS Trust, Walsall WS2 9PS, UK

C Balachandar, Department of Gynaecology, Walsall Hospitals NHS

Trust

C Bayley, Walsall Hospitals NHS Trust

S Ramaiah, Walsall Teaching Primary Care Trust, Walsall WS1 1TE, UK Ethical approval was obtained from Walsall local research ethics committee.
Correspondence to: Dr Y L Hock, Department of Histopathology, Walsall Hospitals NHS Trust, Walsall WS2 9PS, UK; yelin.hock@ walsallhospitals.nhs.uk

Accepted for publication 7 February 2005

\section{REFERENCES}

1 Department of Health (England and Wales). COREC. The use of human organs and tissue. An interim statement. London, Department of Health, April 2003 (www.doh.gov.uk/tissue/interimstatment.pdf).

2 Furness P, Sullivan R. The human tissue bill (editorial). BMJ 2004;328:533-4.

3 Vince G. Pathologists urge tissue law review. Hospital Doctor 6 May 2004; News 13.

4 Benbow EW. Patients, the public and pathologists. London: RCPath, March 26, 2003, ACP News, summer 2003, Meeting reports 54.

5 Broden MS, Konouse DE, Muttman BS, et al. The appropriateness of recommendation for hysterectomy. Obstet Gynecol 2000;95:199-205. 